\title{
A beetle (Carabidae: Chlaenius (Epomis) spp.) that eats frogs
}

\author{
C.H. Scholtz ${ }^{1 *} \&$ C.D. Ralston ${ }^{2}$ \\ ${ }^{1}$ Department of Zoology and Entomology, University of Pretoria, Pretoria, 0002 South Africa \\ ${ }^{2}$ Garden Route Botanical Gardens, 49A Caledon Street, George, 6529 South Africa
}

The large size of most vertebrates compared to that of insects makes it difficult for predatory insects to utilise them as prey and, consequently, very few insects are capable of doing so. The few records of such interactions are usually incidental occurrences limited to young nestling birds or small lizards on land, or small fish and tadpoles in aquatic habitats.

Amongst the more common examples of large insects preying on smaller vertebrates are those of certain aquatic Heteroptera (e.g. Nepidae and Belostomatidae), Odonata and Coleoptera that feed on tadpoles and small fish. Fewer terrestrial insect groups are known to include vertebrates in their diet - one such is the Mantodea in which the few records available suggest the phenomenon is mainly incidental such as when large mantids capture and feed on small lizards. Aggressive ant species have also been recorded to use worker numbers to overwhelm, kill and dismember sedentary nestling birds and rodents.

Here we report on an obligatory association between an insect that is smaller than its vertebrate prey; a terrestrial ground beetle (Carabidae) that feeds on frogs. In this complete role-reversal the frog and beetle exchange their positions as predator/prey in the food chain; the frog from being a generalist insect predator that eats insects similar to its predator, to becoming the prey of a specialist, frog-eating beetle in what is undoubtedly one of the most unusual and bizarre examples of insect feeding yet recorded in southern Africa.

The beetle concerned is one of two species of the genus Chlaenius (Licininae: Chlaeniini), a very large genus (about 1000 species) distributed across the Holarctic and Afrotropical regions. The genus is divided into about 60 subgenera of which one, Chlaenius (Epomis) concerns us here. The subgenus has about 20 species recorded from the Palearctic and Afrotropical regions, two of which, (C. (E.) circumscriptus Duftschmid and C. (E.) simba Alluaud) are known from South Africa. Chlaenius (E.) circumscriptus is widespread in the southern Palearctic Region including Europe and the Near

*Author for correspondence. E-mail: chscholtz@zoology.up.ac.za
East, and across Africa to the Cape. Chlaenius (E.) simba is restricted to southern Africa. They are large beetles, measuring between $16-25 \mathrm{~mm}$ in length (all from Kirschenhofer 2010).

The interactions recorded here were observed by one of us (C.D.R.) in the vicinity of George on the southern Cape coast of South Africa.

Larvae were observed attached to painted reed frogs (Hyperolius marmoratus verrucosus) on three daytime occasions between late December 2015 and late January 2016. On one occasion a larva was attached below a frog's eye, on another to the belly and, on the third, to the front femur (Fig. 1). In the first example, the frog hopped away when disturbed, with the larva still attached, although the frog showed signs of discomfort. In the second case, the larva detached from the host when it was handled and was retained - the frog appeared unharmed but the larva died a day later. The third host-parasite interaction was first observed with a frog sitting quietly in the normal, vertical, position with the larva attached. Other than occasional flexing of its body and the excretion of a milky substance, the larva appeared immobile. After about three hours the frog began to move and was

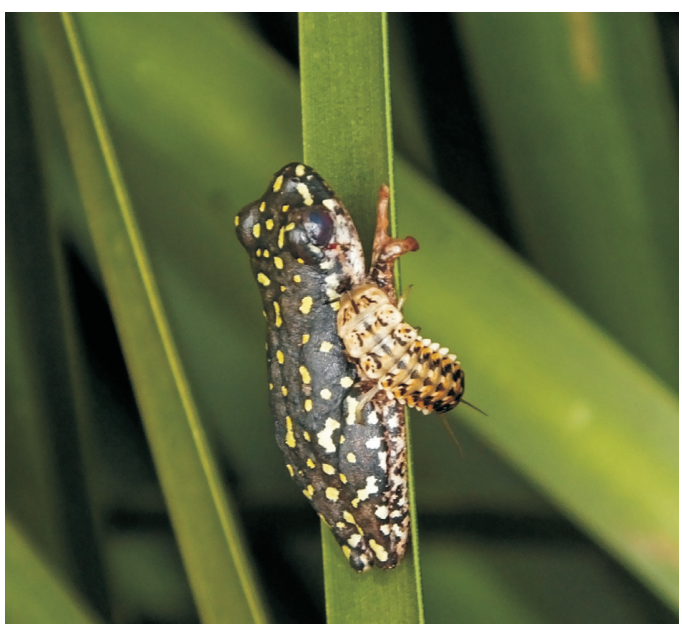

Fig. 1. Photograph of a painted reed frog (Hyperolius marmoratus verrucosus) parasitised by a Chlaenius, probably C. simba (Carabidae) larva from George in the southern Cape. 
collected, with the larva still attached. About five hours after the interaction was first seen, the frog began to move weakly and to try to dislodge the larva but it died soon after. Then the behaviour of the larva changed abruptly and dramatically, from passive attachment to very actively moving around the body of the frog, clearly chewing on body tissues on the belly, leg and head and switching feeding sites regularly. Feeding continued for at least another eight hours. The larva was kept alive but died after a few days.

Predation of frogs by Chlaenius (Epomis) has been recorded in Japan (Chlaenius (E.) nigricans Wiedemann) and by C. circumscriptus and C. (E.) dejeani Dejean \& Boisduval in Israel (Elron, Shlagman \& Gasith 2007; Wizen \& Gasith 2011a, b, c). The larvae of the two Israeli species have been described (Wizen \& Gasith 2011b). In common with their relatives, they undergo three instars. In all cases recorded the beetle larvae and adults prey on frogs; in larvae the association is obligatory in which they start life as an ectoparasite of their frog host where they feed only on blood, developing as they mature into a blood- and tissue-feeder, and finally, tissue only. In adults, the predatory association is facultative, with adults eating insects and, when encountered, killing and eating frogs. Adults and larvae share the same moist habitats as their potential host. Larvae in Israel were most active in mid-summer when amphibian metamorphs emerged from the water. They fed on metamorphs of five amphibian species including three anurans (frogs) and two urodeles (salamanders and newts). It would appear from our observations that the South African species are also most active in mid-summer.

The first South African record of a carabid larva parasitic on a frog was from Port Elizabeth (Moore 1971). Two blood-red larvae were found attached to the same hind leg of an apparently healthy 'garden toad' (probably the common species in the area, Amietophrynus rangeri). Although the identity of the larvae was unknown, they were keyed to the group currently considered to be members of the Chlaeniini. The large size of the larvae, which were deduced to be in the first instar because of the presence of egg-bursters on the head, suggested one of only a few possible species from the area, one of which was thought to be a Chlaenius (recorded as Epomis) species.

Larvae are sit-and-wait predators that attract approaching frogs by antennal and mouthpart- waving in a form of aggressive mimicry (where a predator communicates with its prey by making signals to indirectly manipulate prey behaviour (Jackson \& Cross 1987)), similar to that displayed by anglerfish which wriggle a dorsal spine to mimic a small worm or shrimp that serves as a lure to attract fish prey.

The larvae have unusual, double-hooked mandibles (Fig. 2) which enable them to attach firmly to the frog's body. These, and the antennae are simultaneously moved sideways and rotated, first on one side of the head, then the other. Furthermore, the larvae have a group of six very large stemmata on each side of the head capsule (Fig. 3), which suggests that they have reasonable vision, an obvious requirement for the predatory behaviour discussed below. Most beetle larvae, on the other hand, have small stemmata that, at best, distinguish between light and dark (Chapman 1969).

Predatory larval behaviour commences when a frog approaches (based on numerous experimental encounters recorded by Wizen \& Gasith 2011c) by starting to wave its mandibles-antennae to attract the frog's attention. These movements increase in frequency as the frog nears the larva. When the frog gets to within striking distance of its protracted tongue it lunges at the 'prey' but the larva retaliates by attaching onto the frog, usually on the mouth or areas of the upper venter. After attaching, larvae

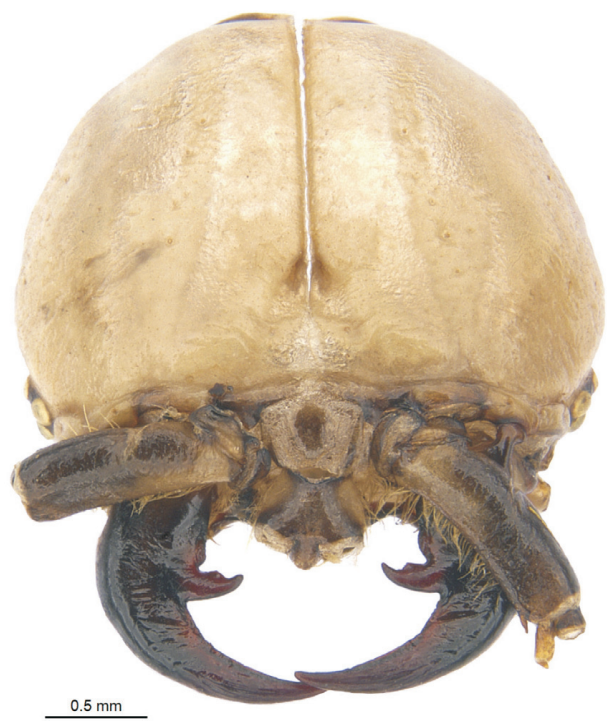

Fig. 2. Photograph of head capsule of Chlaenius, probably $C$. simba (Carabidae), in dorsal view, illustrating mandible shape. 


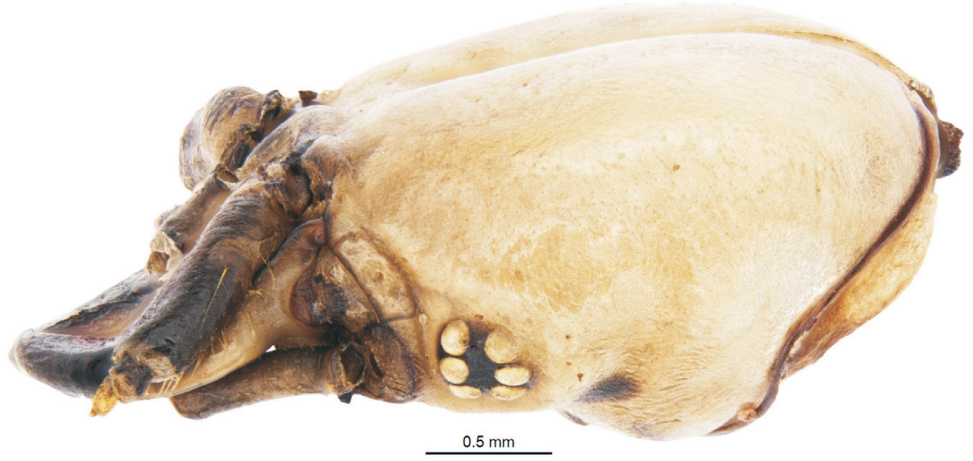

Fig. 3. Photograph of head capsule of Chlaenius, probably C. simba (Carabidae), in lateral view, illustrating large stemmata.

would sometimes reposition on the frog. In several instances Wizen \& Gasith (2011c) recorded that frogs successfully swallowed larvae but these were soon regurgitated after which they immediately attached to the host and started feeding. In one bizarre case, a frog swallowed a larva which could be seen moving in the frog's abdomen for about two hours after which the frog regurgitated it whereupon it promptly attached to the frog and eventually ate it! Larvae consume most of the frog except the bones. The frogs recorded in the Israeli studies were 5-20 times heavier than the beetle larvae.

Larvae stop feeding and detach from the stillliving host (probably only first instar) at the end of the instar, moult in a sheltered site on the ground after which a new host has to be located and attacked. This is repeated at the end of each instar. Larval duration is fast for such a large insect. In the Israeli species, C. dejeani, duration of the first instar was $4-7$ days, second, $3-5$ days and third, 2-4 days. From the end of the third instar, when larvae enter the soil to pupate, until the adult emerges takes about three weeks for a total life-cycle of less than 40 days during which four prey are fed on (Wizen \& Gasith 2011c). The Japanese, C. nigricans completes its life-cycle in about 30 days and feeds on three prey (Shiina \& Tachikawa 1988, according to Elron et al. 2007).

Adult beetles attack their amphibian prey, usually by jumping onto its back and biting into the lower back muscles. Although the frog tries to dislodge the attacker by jumping, movement ceases within 1-2 minutes after which the beetle consumes the frog, leaving only bones (Wizen \& Gasith 2011c).

The identity of the larvae from George (this study) was deduced on the basis of Moore (1971) who illustrated the head capsule of the specimens collected off the toad in Port Elizabeth and Wizen \& Gasith (2011c) who illustrated those of the two Israeli species. According to the Israeli authors, the mandibles of the two species are characteristically different, especially in the shape of the main and accessory tooth on the cutting edge of the mandible. These differences are clearly visible in the illustrations in their paper. Comparison of the Port Elizabeth, Israeli and George specimens suggest that the Port Elizabeth species was very likely C. circumscriptus while the George species is undoubtedly a different species. By elimination, this could then only be C. simba (Fig. 4c).

In South Africa, three frog species have been recorded as beetle hosts or prey; a 'garden toad' (probably Amietophrynus rangeri) from Port Elizabeth, the clicking stream frog (Strongylopus grayii), from Cape Town and Knysna and the painted reed frog (Hyperolius marmoratus verrucosus) from George. Consequently, it would appear that, as in Israel, most frog species are suitable as hosts/prey.

Most insects that utilise vertebrates as food do so as parasites that feed on the host's blood, which is the most common source of liquid food, although some also utilise other liquids, such as lachrymal fluid. Parasitism of vertebrates by insects is common and whole major groups have specialised in such lifestyles; both as internal parasites (e.g. many Diptera, including the bot flies) and externally (e.g. all lice-Psocodea, and adult fleas-Siphonoptera). Parasites may spend their entire life-cycle on their host (continuous parasites e.g. lice), or part of their life-cycle on the host, and part as free-living insects (transitory parasites, e.g. fleas), or they visit the host only to feed (intermittent or temporary para- 


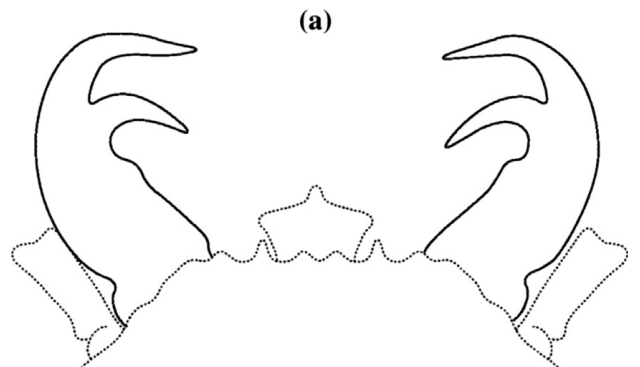

(b)

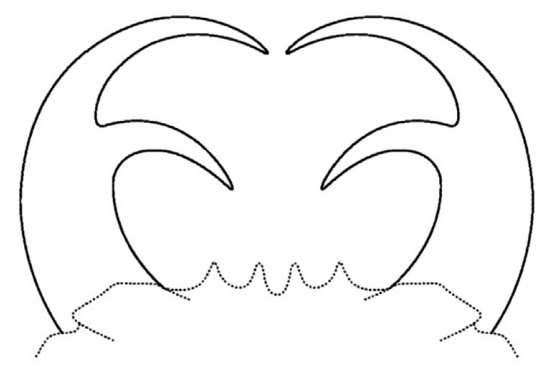

(c)

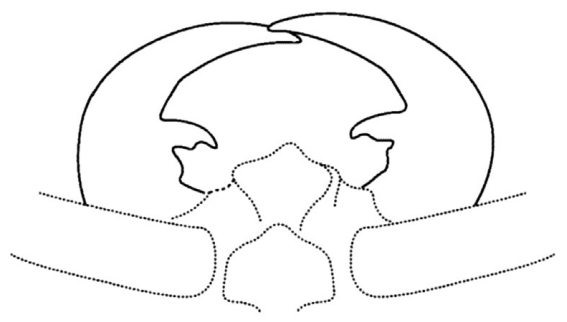

Fig. 4. Drawings of mandible shape of different Chlaenius (Carabidae) species: a, C. dejeani (Israel; redrawn from Wizen \& Gasith 2011c); b, C. circumscriptus (Israel and Port Elizabeth; redrawn from Wizen \& Gasith 2011c, and Moore 1971, respectively); c, Chlaenius, probably $C$. simba, from George (this study).

sites, e.g. blood-feeding Diptera such as mosquitoes). Parasites that feed continuously are most host-specific, and those that feed intermittently, least so. Parasites seldom directly cause the death of their host while predators always do. Insect predation of vertebrates, on the other hand, is uncommon and invariably facultative while obligatory predation by one insect group on a certain vertebrate is virtually unheard of.
In the example reported on here, a beetle larva starts out life as a non-lethal, blood-feeding ectoparasite of any of several possible frog hosts. Then, during its development it changes from bloodfeeding to feeding on host blood and tissue, and finally to tissue only, killing and consuming its host and completing the transition from a typical parasite to a normal predator in what must surely rate as one of the most unusual and bizarre parasite/predator-prey interactions.

\section{ACKNOWLEDGEMENTS}

We thank M. Wilson and R. Stals for helping to identify the beetle, G. Swart for donation of a dead larva and of photographs, P. Schule for Carabidae literature, L. Minter for information on frogs, M. Kaplan for drawing our attention to the presence of a parasitised frog in the George Botanical Gardens, W. Strümpher for the head capsule photographs, H. de Klerk for editing the photographs of the frog and parasite, and A. Olwage for the mouthpart illustrations.

\section{REFERENCES}

CHAPMAN, R.F. 1969. The Insects: Structure and Function. The English Universities Press. London, U.K.

JACKSON, R.R. \& CROSS, F.R. 1987. A cognitive perspective on aggressive mimicry. Journal of Zoology 290(3): 161-171.

KIRSCHENHOFER, E. 2010. Beitrag zur kenntnis afrotropischen Chlaeniini. Acta Coleopterologica 24(2): 4-42.

MOORE, B.P. 1971. Notes on an extraordinary bloodfeeding carabid larva (Coleoptera) from Port Elizabeth. Annals of the Natal Museum 20(3): 479-482

ELRON, E., SHLAGMAN, A. \& GASITH, A. 2007. First detailed report of predation on anuran metamorphs by terrestrial beetle larvae. Herpetological Review 38(1): 30-33.

WIZEN, G. \& GASITH, A. 2011a. Predation of amphibians by carabid beetles of the genus Epomis found in the central coastal plain of Israel. Zookeys 100: 181-191.

WIZEN, G. \& GASITH, A. 2011b. Color variability and body size of larvae of two Epomis species (Coleoptera, Carabidae) in Israel, with a key to the larval stages. Zookeys 119: 37-52

WIZEN, G. \& GASITH, A. 2011c. An unprecedented role reversal: ground beetle larvae (Coleoptera: Carabidae) lure amphibians and prey upon them. PLOS ONE 6(9): e25161

Accepted 23 February 2017

\section{APPENDIX 1. Additional material}

The observations reported here were first brought to the attention of the public by recordings on iSpot southern Africa, a community interactive web-based biodiversity platform. These recordings can be viewed at: http://www.ispotnature.org/node/631799 / http://www.ispotnature.org/node/770203 http://www.ispotnature.org/node/762845 